\title{
Status and Spatial Visualization of Toxic Pollutants (BTEX) in Urban Atmosphere
}

\author{
Muhannad Mansha", Anwar Rashid Saleemi, Javed Hassan Naqvi \\ Department of Chemical Engineering, University of Engineering \& Technology, Lahore, Pakistan \\ E-mail:"Muhammad_mansha@uet.edu.pk \\ Recieved March 3, 2011; revised April 24, 2011; accepted May 3, 2011
}

\begin{abstract}
This is a study of visualization of positive data of by Positive Modified Quadratic Shepard (PMQS) method. This data visualization tool was implemented successfully in MATLAB using both recorded pollutants levels and geological coordinates of data acquisition points located in different localities of the metropolitan. These points were located in/around the potential air emissions sources like vehicular transport, industrial sector and residential sector dispersed all around the city Field measurements were carried for 12 hour (day time) at eight points each. An online VOC analyzer was used during field campaign to collect data of hazardous organic pollutants like benzene, toluene, ethyl benzene, xylene (BTEX). Constant concentration curves were generated in form of contour plots showing latitude, longitude and spatial distribution of recorded atmospheric pollutants.
\end{abstract}

Keywords: Spatial Distribution, Hazardous Air Pollutants, Contour Plot, Data Acquisition, Emission Sources

\section{Introduction}

Urbanization is taking place throughout the world, at an unpredictable pace. Increasing urban population and growing levels of industrialization have inevitably led to a series of environment-related problems, one of which is worsening air quality. The urban and industrialized culture has not only increased the sources of air pollution but also added to types of pollutants in ambient air. Air pollution is no longer restricted to conventional air pollutants viz. sulphur dioxide and oxides of nitrogen, ammonia, hydrogen sulphide, respirable particulate matter and ozone. The various urban activities have added to the list of ambient air pollutants a class of compounds, Volatile Organic Compounds (VOCs). Environmental Protection Agency has identified 41 VOCs in ambient air. Some of them are proven carcinogens and mutagens, while some are suspected of having human health effects ranging from carcinogenicity to neurotoxicity. VOCs also contribute to the formation of ground level ozone and smog $[1,2]$ and benzene is one such VOC. study on Air toxics related to vehicular emission [3] establishes benzene in air as a pollutant strictly related to industrial activities and automotive emissions. Efforts to reduce the lead content of the fuel gasoline and to maintain the octane number has led to an increase in benzene and other aromatic hydrocarbons in gasoline. An increase in the concentration of these chemicals in the air as primary pollutant and as precursors of photochemical smog is an obvious result [4]. Most of organic pollutants are of great concern today due to severe short term and long terms hazardous effects [5]. The common types of these pollutants include Volatile Organic Compounds (VOCs), Poly Aromatic Hydrocarbons (PAHs) and Polychlorinated biphenyls (PCBs). The various aspects of aromatic compounds such as benzene, toluene, ethyl benzene and Xylene, present in ambient atmosphere, were studied by the scientist/researchers all over the worlds. In these studies, Benzene has identified as carcinogenic when exposed to high levels in ambient air. A study conducted in 2004, report high benzene concentrations in two Asian cities of Bangkok and Manila [6]. In Bangladesh, the reported ambient benzene concentration was up to $10,560 \mu \mathrm{g} / \mathrm{m}^{3}$ [7]. Benzene was also identified as major toxic pollutants in two major Indian cities of Mumbai $\left(9.39-103.6 \mu \mathrm{g} / \mathrm{m}^{3}\right)$ and Dehli $\left(21-26 \mu \mathrm{g} / \mathrm{m}^{3}\right)[8,9]$.

A number of air quality assessment studies have been conducted in Lahore by various international/national organizations such as Pakistan Space and Upper Atmosphere Research Commission [10-12], Japan International Cooperation Agency and Punjab Environment Protection Department [13]. These studies concluded that there was 
a threatening situation of deterioration of air quality in the city. In these studies, the issues of air pollution have been addressed regarding criteria pollutants as $\mathrm{CO}, \mathrm{NO}_{\mathrm{x}}, \mathrm{SO}_{2}$, Suspended Particulate Matter (both $\mathrm{PM}_{10}$ \& TSP) and surface ozone $\mathrm{O}_{3}$. There was no information/data available regarding the toxic air pollutants such as benzene, toluene, xylene and ethyl benzene. The situation become more worsens as growing use of benzene [14] in oil (4\% $4.7 \%$ by volume) for octane enhancer by all Pakistan national refineries (Table 1).

\subsection{Theoretical Overview of Modified Quadratic Shepard (MQS) Method}

Common visualization methods require an underlying grid. For visualization of scattered data samples it is required to approximate the data at the same grid using some interpolation technique. It is common that the data samples are positive and representing the quantities for which negative value is meaningless. For example mass, volume and density are meaningless when negative. Modified Quadratic Shepard method is a commonly used method for gridding purposes. However it does not preserve positivity for inherently positive data sets. Key requirement for an algorithm to be used for real time application is its predictable timing behavior. Here an efficient and deterministic alternative Quadratic Shepard Method as a solution to the problem of visualization of multivariate positive data in real time [15].

\subsection{An Overview of Modified Quadratic Shepard (MQS) Method}

Modified Quadratic Shepard (MQS) Method is an inverse distance weighted method that is based on the approach introduced by Shepard [16]. Let a set of $\mathrm{N}$ non-negative data values, $f_{i}$, at associated scattered sampling locations, $X_{i}=\left(x_{1 i}, x_{2 i}, x_{3 i}, \cdots\right)$, where $i=1,2, \cdots, N$ is given. Shepard interpolant is defined as follows;

$$
F(X)=\frac{\sum_{i=1}^{N} w_{i}(x) f_{i}}{\sum_{i=1}^{N} w_{i}(x)}
$$

where

Table 1. Physical properties of gasoline in pakistan.

\begin{tabular}{lccccc}
\hline Parameter & ARL & NRL & PRL & Dhodak & PARCO \\
\hline RVP (psia) & 7.2 & 7.3 & 7.3 & 6.9 & 7.4 \\
Benzene (vol\%) & 4.6 & 4.2 & 4.3 & 3.6 & 4.0 \\
Total aromatics (vol\%) & 41 & 38 & 39 & 32 & 32 \\
\hline
\end{tabular}

$$
\begin{gathered}
w_{i}(x)=\frac{1}{d_{i}(x)} \\
d_{i}(x)=\left[\left(x_{1}-x_{1 i}\right)^{2}+\left(x_{2}-x_{2 i}\right)^{2}+\cdots\right]
\end{gathered}
$$

and $F(X)$ is bounded between maximum and minimum values in the data set [17]. Although this interpolant provides one of the solutions to the problem of visualization of positive data; however it is not a suitable choice for many visualization applications. This interpolant has an unnecessary property that slop at each reference point is zero.

$$
F(x)=\frac{\sum_{i=1}^{N} w_{i}(x) Q_{i}(x)}{\sum_{i=1}^{N} w_{i}(x)}
$$

Numbers of modifications were suggested to overcome the drawbacks of the original Shepard's method. The most interesting modification for data visualization perspective is due to Frank and Neilson [18]. They improved continuity of the method by replacing constant basis function, $f_{i}$, by the quadratic basis function, $Q_{i}(X)$, with the following characteristics:

1) $Q_{i}(x)$ is inverse distance weighted least square fit to the other data points. This made the method a $\mathrm{C} 1$ continuous method.

2) $Q_{i}(x)=f_{i}$ This constraint forces $Q_{i}(x)$ to interpolate the corresponding data value.

The resulting interpolant called Modified Quadratic Shepard interpolation function, $F(X)$, is defined as follows:

The basic function $Q_{i}(X)$ is defined as follows:

$$
Q_{i}(x)=f_{i}+g_{i}^{T}\left(x-x_{i}\right)+\frac{1}{2}\left(x-x_{i}\right)^{T} A\left(x-x_{i}\right)
$$

The Matrix, Ai, is Hessian Matrix of the quadratic basis function and $g^{T}$ is the gradient vector. The modifications given above not only improve continuity of the interpolant but also eliminate the problem of missing data values with the original Shepard method.

The objective of the current study to determine the baseline concentrations of toxic pollutants (BTEX) and their spatial distribution by implementing Modified Quadratic Shepard in urban atmosphere of Lahore (second largest city of Pakistan) from various potential emission sources.

\section{Material and Methods}

Ground base data of BTEX pollutants was collected using an online analyzer (VOC Analyzer, Model: 71M-PID, Environment SA-France) and spatial distribution of the 
pollutants was studied by PMQS method implemented in MATLAB. The implementation of this method in MATLAB to visualize the collected data was novelty of this part of our urban air quality study of metropolitan Lahore.

The analyzer measures the concentrations of hazardous air pollutants including benzene, toluene, ethyl benzene, xylene by default configurations and there were options to measure the concentrations of other pollutants such as 1-3 Butadiene, Cyclohexane, n-heptane, n-pentane, Styrene by setting manual configurations. The analyzer collect the air sample after 15 minutes (selected) in cycle, analyze it and give the measurements on display or could be saved in computer directly from the analyzer in real time. The ambient concentration data of these compounds were collected at eight different sites as shown in Figure 1 and other relevant information is given in Table 2.
A MATLAB program for PMQS methods to visualize the BTEX data was executed successfully. Input data file contains pollutants concentrations (in $\mu \mathrm{g} / \mathrm{m}^{3}$ ) and geological coordinates (latitude and longitude) and this data file (in MS-Excel format) is loaded in the developed program. This program/model generate distribution plot in form of contour plot which consists of constant concentration curves.

Data quality assurance was most essential part of field measurements. Data quality was assured by two ways, 1) by instrument calibration and before commencing field campaign, analyzer was calibrated by certified Zero Air Gas having concentrations of $0.01 \mathrm{ppb}$ and Span Air Gas with concentration of $35 \mathrm{ppb}$. The analyzer read concentrations both calibration gases as $0.02 \mathrm{ppb}$ and $34.99 \mathrm{ppb}$ respectively. Nitrogen gas (having purity of GC-grade; 99.999\%) from M/s BOC Pakistan, was used as carrier for the VOC analyzer. Moreover, the instrument has built

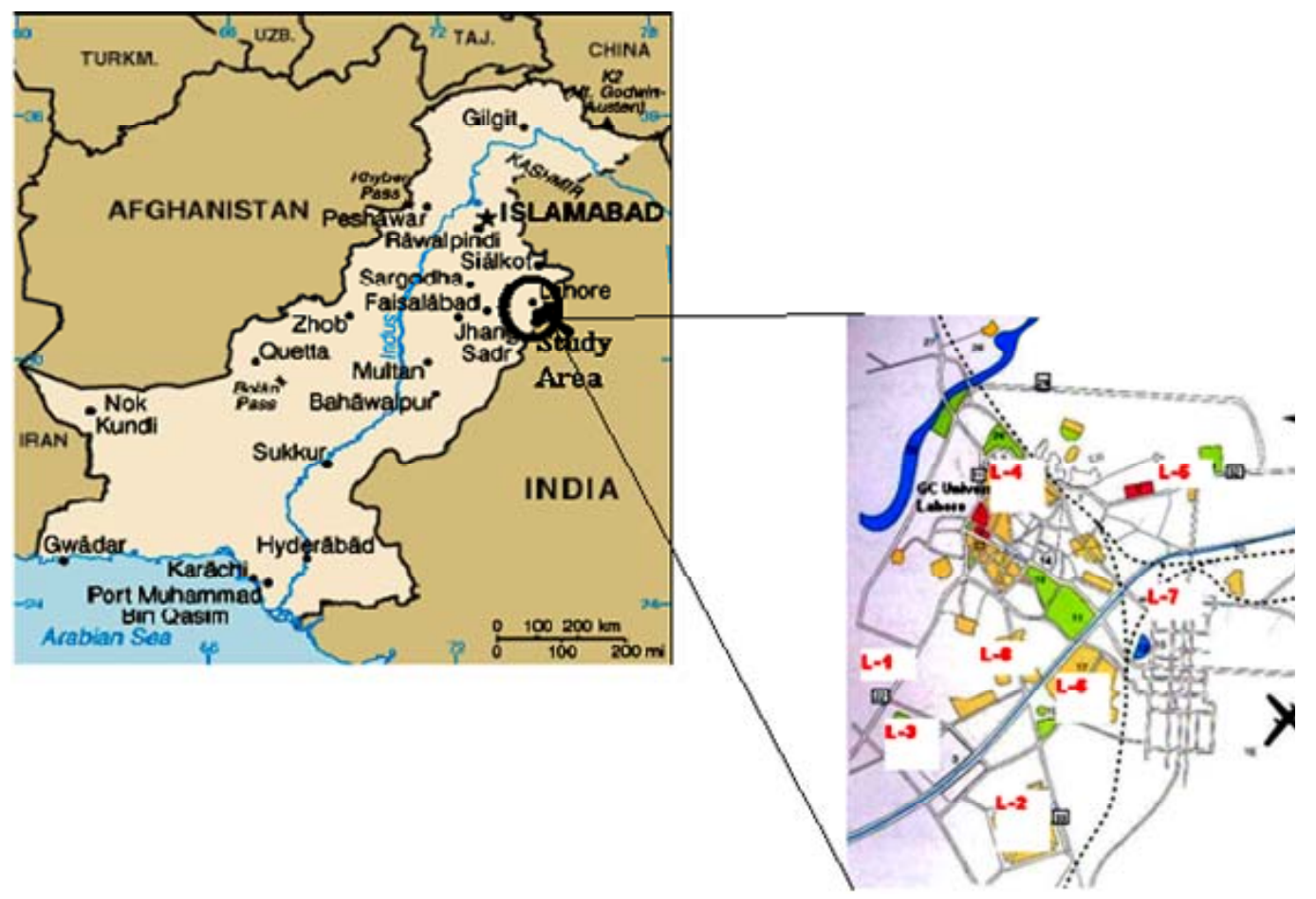

Figure 1. Pakistan map showing metropolitan lahore (study area).

Table 2. Selected locations and their geological coordinates.

\begin{tabular}{|c|c|c|c|c|c|}
\hline \multirow{2}{*}{\multicolumn{2}{|c|}{ Sr. No. Location ID }} & \multirow{2}{*}{ Site Location } & \multirow{2}{*}{$\begin{array}{l}\text { Site Surroundings/Major } \\
\text { Possible Emission Sources }\end{array}$} & \multicolumn{2}{|c|}{ Location Geological Coordinates } \\
\hline & & & & Latitude & Longitude \\
\hline 1 & L-1 & Kotlakhpat Ind. Area & Industry & $31^{\circ} 27^{\prime} 36.05^{\prime \prime} \mathrm{N}$ & $74^{\circ} 18^{\prime} 33.03^{\prime \prime} \mathrm{E}$ \\
\hline 2 & L-2 & Model Town & Residential & $31^{\circ} 28^{\prime} 36.50^{\prime \prime} \mathrm{N}$ & $74^{\circ} 19^{\prime} 16.19^{\prime \prime} \mathrm{E}$ \\
\hline 3 & L-3 & Chowk Yateem Khana & Vehicular Traffic & $31^{\circ} 31^{\prime} 55.36 " \mathrm{~N}$ & $74^{\circ} 17^{\prime} 16.01 " \mathrm{E}$ \\
\hline 4 & L-4 & Azadi Chowk & Vehicular Traffic & $31^{\circ} 35^{\prime} 12.97 " \mathrm{~N}$ & $74^{\circ} 18^{\prime} 33.82^{\prime \prime} \mathrm{E}$ \\
\hline 5 & L-5 & Eng. University & Vehicular Traffic & $31^{\circ} 34^{\prime} 46.93 " \mathrm{~N}$ & $74^{\circ} 21^{\prime} 21.89^{\prime \prime} \mathrm{E}$ \\
\hline 6 & L-6 & Canal Road & Vehicular Traffic & $31^{\circ} 28^{\prime} 57.95 " \mathrm{~N}$ & $74^{\circ} 17^{\prime} 32.75^{\prime \prime} \mathrm{E}$ \\
\hline 7 & L-7 & Air Port & Residential & $31^{\circ} 31^{\prime} 38.26^{\prime \prime} \mathrm{N}$ & $74^{\circ} 24^{\prime} 28.39^{\prime \prime} \mathrm{E}$ \\
\hline 8 & L-8 & Ichra & Vehicular Traffic & $31^{\circ} 31^{\prime} 30.32^{\prime \prime} \mathrm{N}$ & $74^{\circ} 19^{\prime} 27.97^{\prime \prime} \mathrm{E}$ \\
\hline
\end{tabular}


in capability of calibration (internal calibration) during operation. 2) Data quality was ensured through field data $\log$ books, site visitors log book.

\section{Results and Discussion}

The measurements were carried out at 5 - 7 feet height from ground at each location. The online analyzer collect air sample for 15 minutes alternatively in two sampling tubes. The collected sample was analyzed through gas chromatographic technique and detected by PID detector based retention time of each compound. Fifteen minute data of each measuring pollutants was plotted in time scale variation as shown in Figures 2-9. The temporal variation plot of each pollutant indicates the behavior during the day \& night under the prevailing meteoro- logical conditions at each site. It was observed that the levels of each pollutants increases during the mid day when the traffic in the city is at full swing. This also increases the atmospheric ozone due to the reaction of BTEX compounds and oxides of nitrogen in the presence of sunlight. The average meteorological conditions are plotted as wind rose as shown in Figure 10.

The maximum levels of benzene, ethyl benzene and Xylene were $53.17 \mu \mathrm{g} / \mathrm{m}^{3}, 89.10 \mu \mathrm{g} / \mathrm{m}^{3}$ and $19.6 \mu \mathrm{g} / \mathrm{m}^{3}$ respectively at Kotlaphpat Ind. Area where as Toluene was of $33.17 \mu \mathrm{g} / \mathrm{m}^{3}$ at Ichra. The selected monitoring sites were representatives of possible emission sources (Table 2) like vehicular transport (Chowk Yateem Khana, Azadi Chowk, Ichra and Engg. University), industrial sector (Kot Lakhpat Industrial Area) and residential sector (Canal View Housing Colony, Model

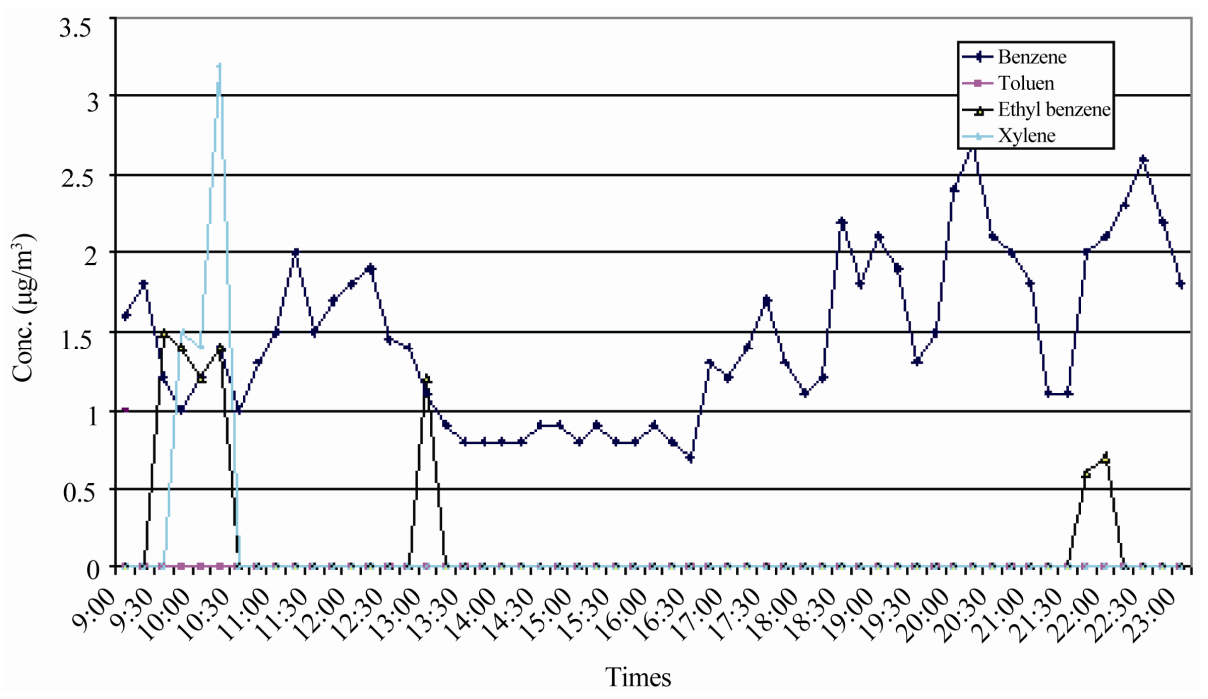

Figure 2. Temporal variation of BTEX at Kotlakhpat (L-1).

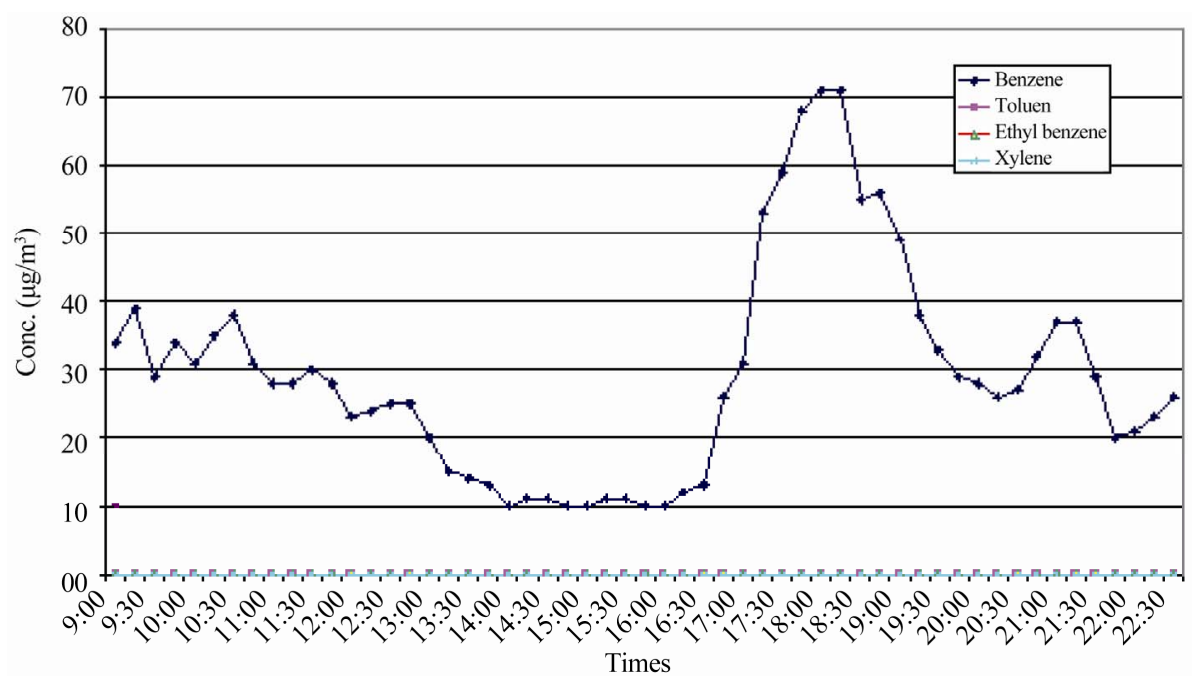

Figure 3. Temporal variation of BTEX at Model Town (L-2). 


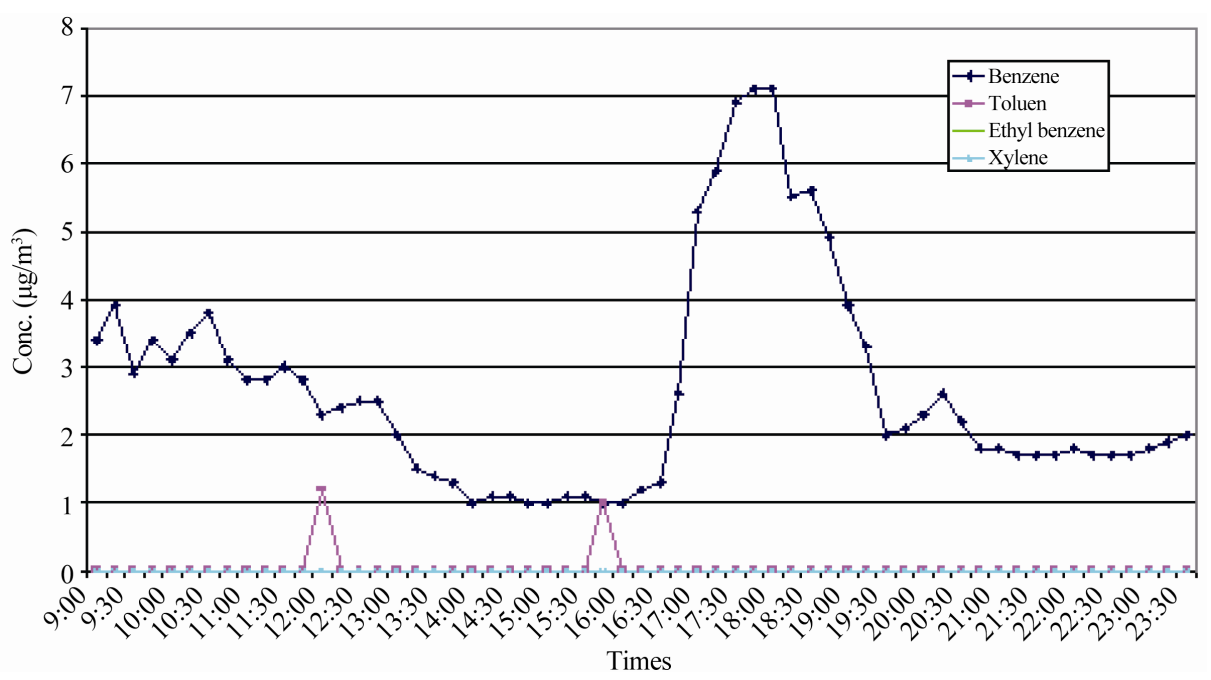

Figure 4. Temporal variation of BTEX at Chowk Yateem Khana (L-3).

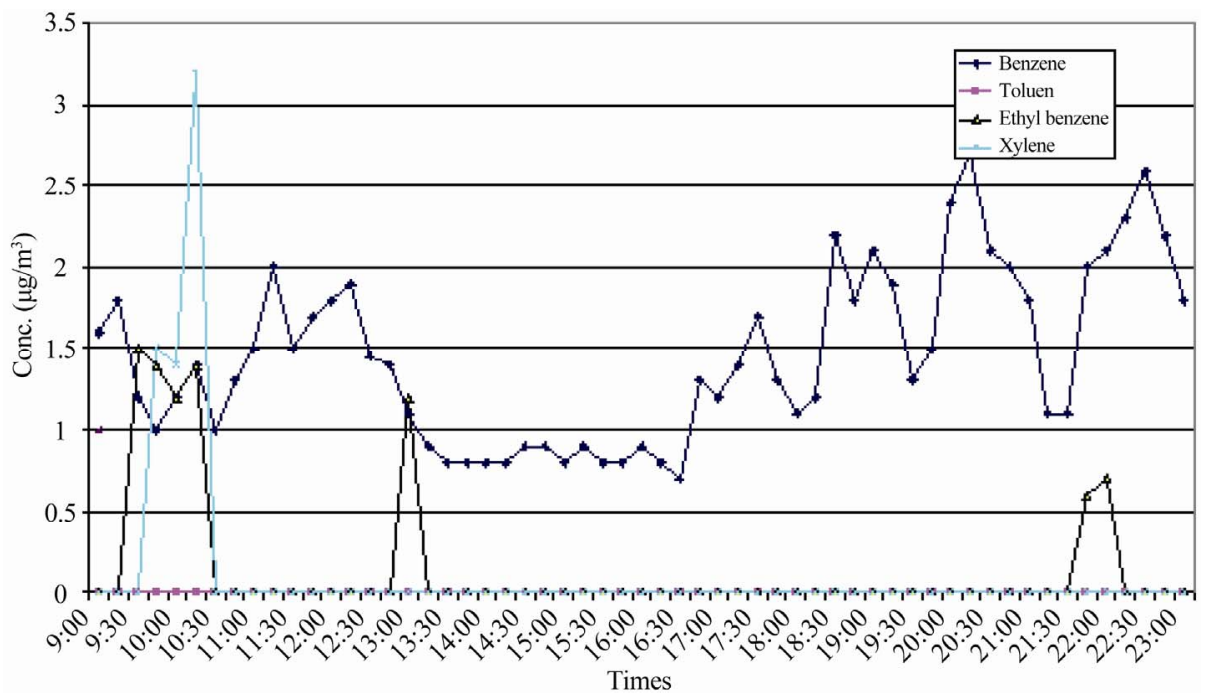

Figure 5. Temporal variation of BTEX at Azadi Chowk (L-4).

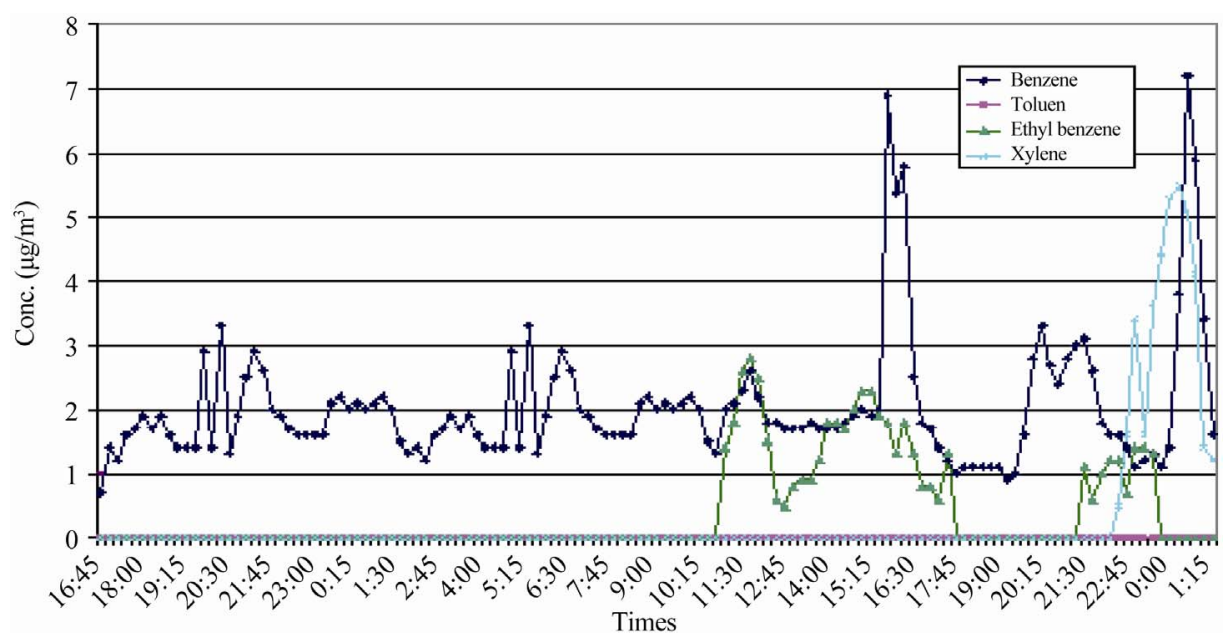

Figure 6. Temporal variation of BTEX at Engg. University (L-5). 


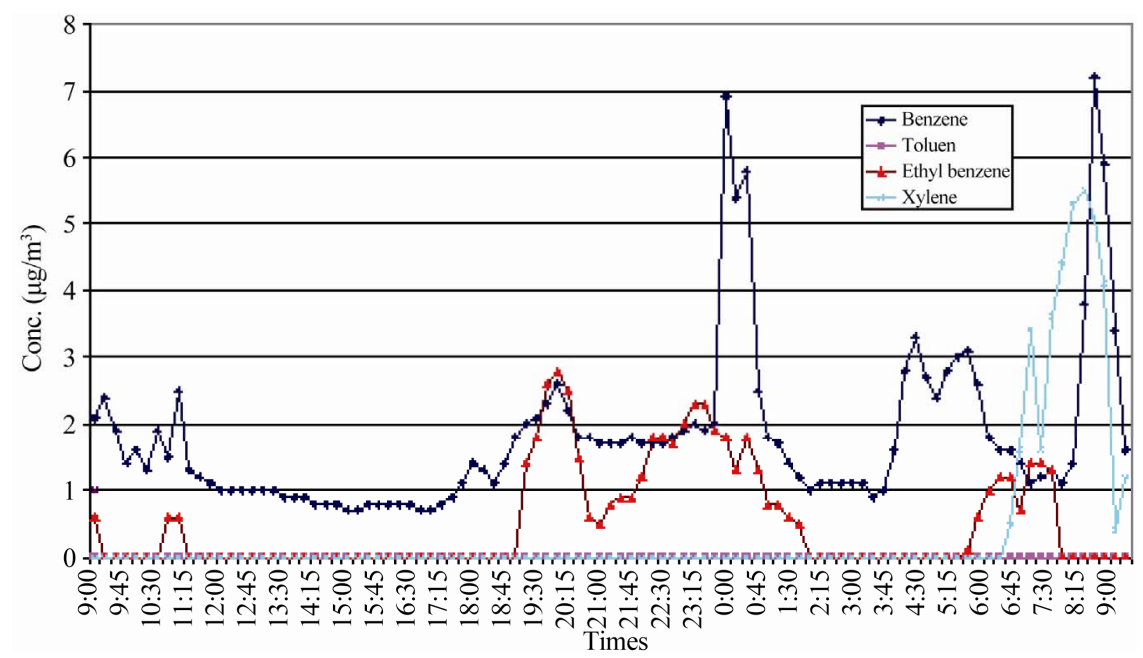

Figure 7. Temporal variation of BTEX at Canal Road (L-6).

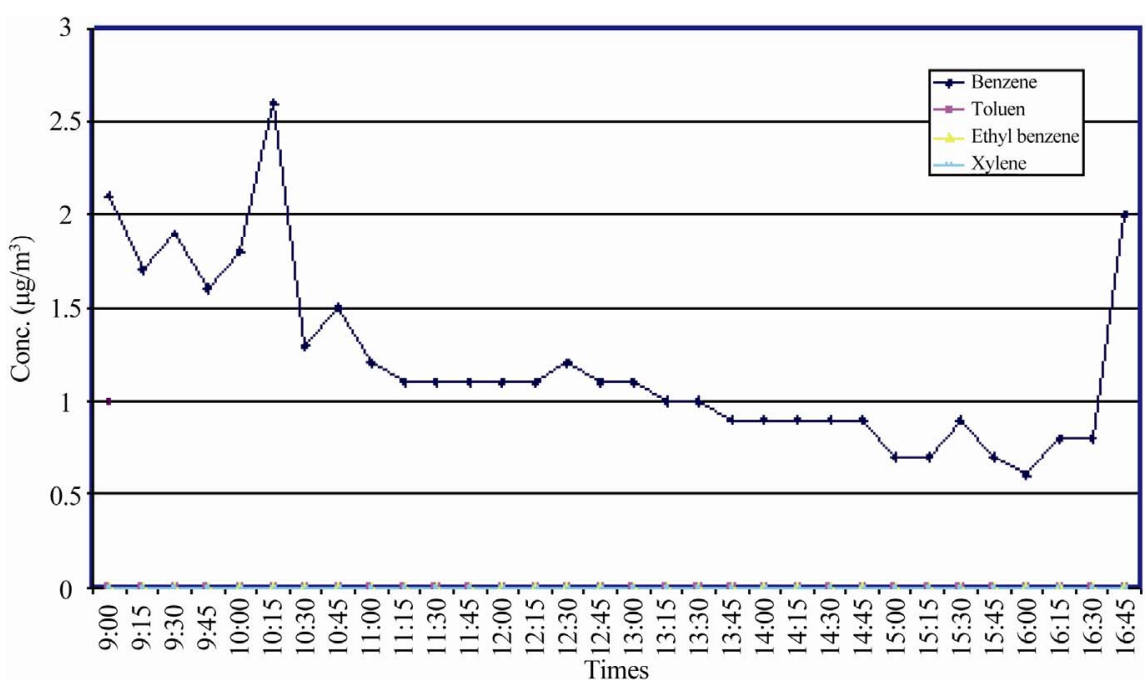

Figure 8. Temporal variation of BTEX at Airport (L-7).

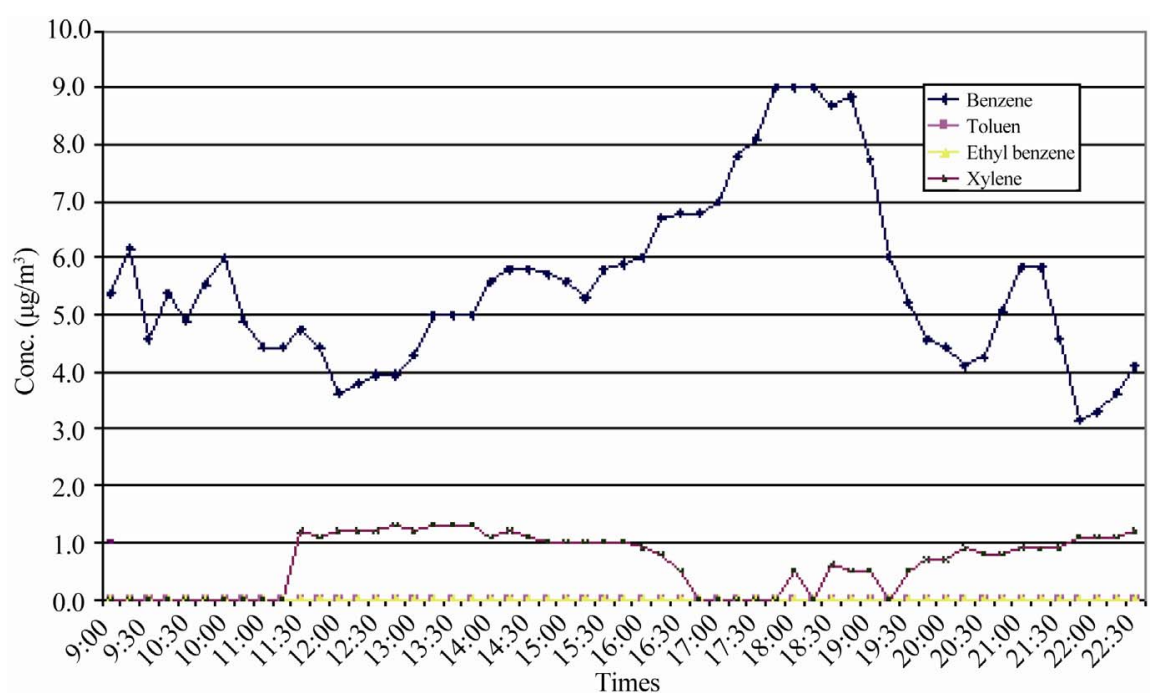

Figure 9. Temporal variation of BTEX at Ichra (L-8). 


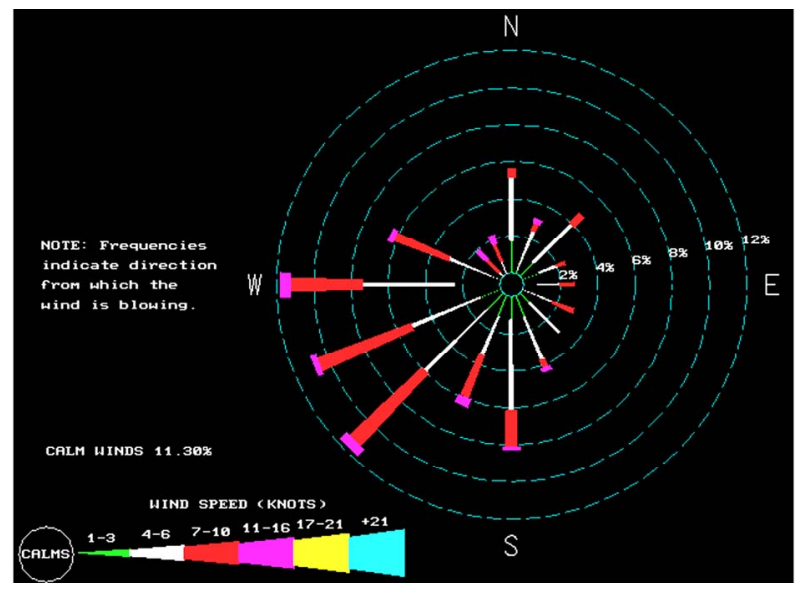

Figure 10. Meteorological data (Temp, Humidity \& Wind Speed) of five monitoring site measured by Mini Met System.

Town \& Air Port). The maximum levels of the pollutnats are given in Table 3 .

Plots in Figures 11-14 show the spatial distribution of Benzene, Toluene, Ethyl benzene and Xylene respect-

Table 3. Maximum levels of btex compounds at measuring sites.

\begin{tabular}{|c|c|c|c|c|c|}
\hline \multirow{2}{*}{$\begin{array}{l}\text { Location } \\
\text { ID }\end{array}$} & \multirow{2}{*}{$\begin{array}{l}\text { Location } \\
\text { Name }\end{array}$} & \multicolumn{4}{|c|}{ Recorded Measurements $\left(\mu \mathrm{g} / \mathrm{m}^{3}\right)$} \\
\hline & & Benzene & Toluene & $\begin{array}{c}\text { Ethyl } \\
\text { benzene }\end{array}$ & Xylene \\
\hline L-1 & $\begin{array}{l}\text { Kotlakhpat Ind. } \\
\text { Area }\end{array}$ & 53.17 & 19.2 & 55.0 & 17.7 \\
\hline L-2 & Model Town & 8.1 & 3.5 & 10.7 & 4.7 \\
\hline L-3 & $\begin{array}{l}\text { Chowk Yateem } \\
\text { Khana }\end{array}$ & 32.6 & 13.9 & 12.0 & 8.5 \\
\hline L-4 & Azadi Chowk & 38.9 & 21.3 & 36.10 & 8.5 \\
\hline L-5 & Engg. University & 15.4 & 8.1 & 17.1 & 8.9 \\
\hline L-6 & Canal Road & 12.3 & 13.9 & 13.7 & 0.0 \\
\hline L-7 & Air Port & 4.3 & 2.6 & 3.7 & 2.7 \\
\hline L-8 & Ichra & 44.2 & 33.17 & 20.1 & 14.15 \\
\hline
\end{tabular}

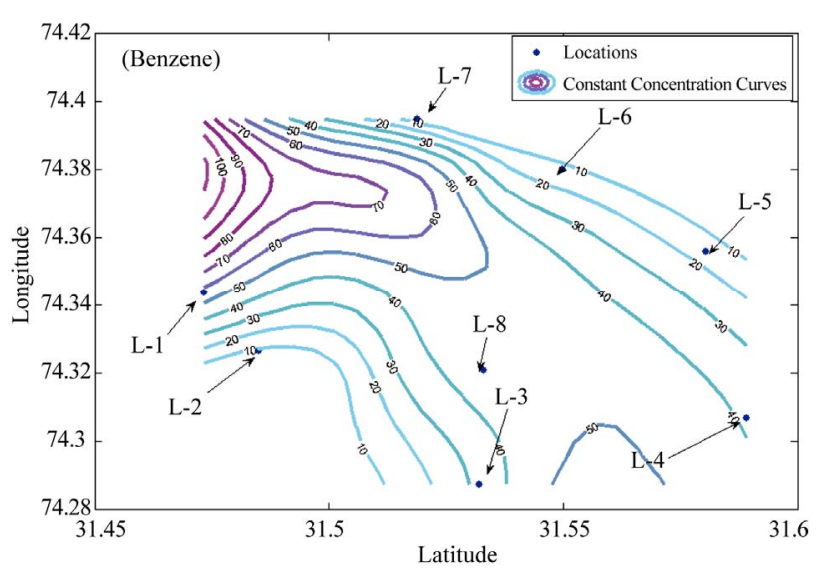

Figure 11. Spatial distribution of benzene over lahore.

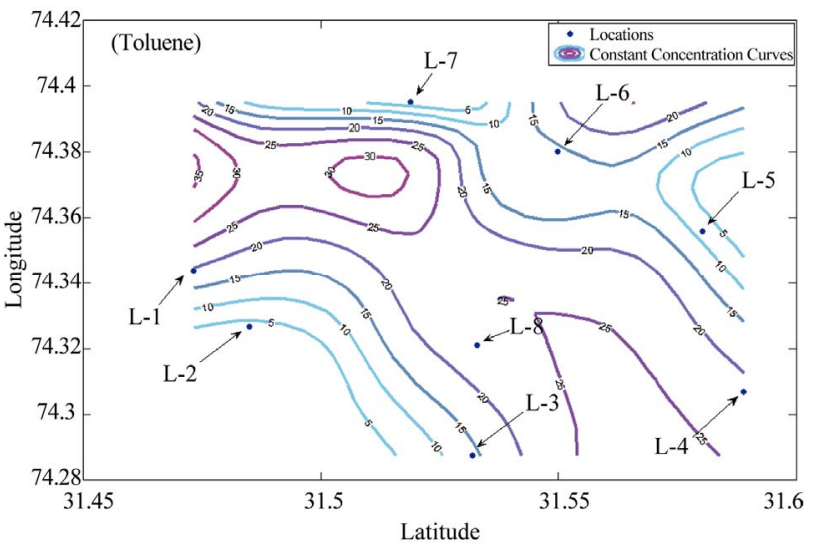

Figure 12. Spatial distribution of toluene over lahore.

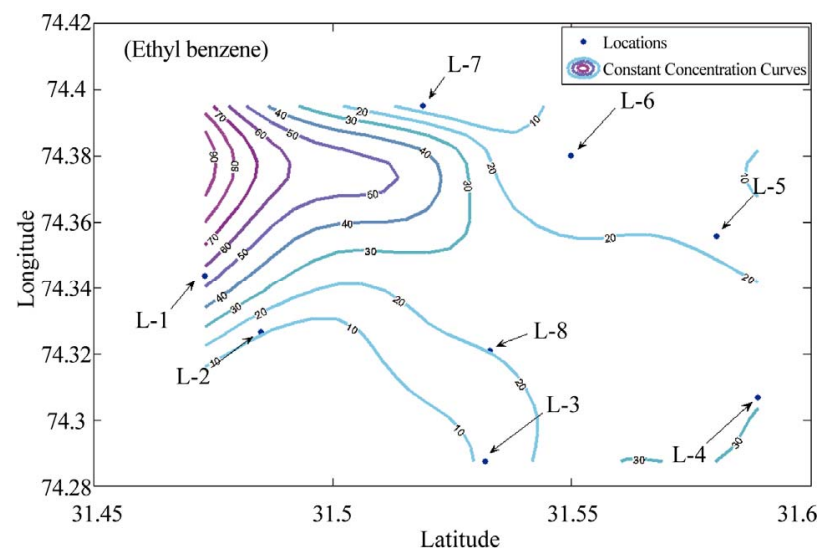

Figure 13. Spatial distribution of ethyl benzene over lahore.

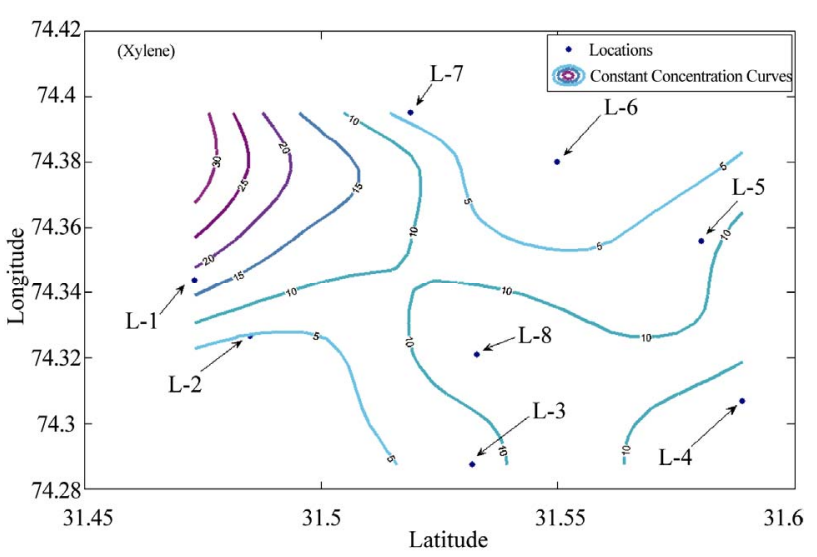

Figure 14. Spatial distribution of xylene over lahore.

tively. In these plots, Latitudes and Longitudes of selected locations were taken in $\mathrm{X}$-axis and $\mathrm{Y}$-axis respectively. The lines in the contour plots show he constant concentration line. There is narrows space between high value concentration lines (for each of BTEX compounds) in surrounding of Location L-1 (Kotlakhpat Ind. Area) with Latitude of $31^{\circ} 27^{\prime} 36.05^{\prime \prime} \mathrm{N}$ and $74^{\circ} 18^{\prime} 33.03^{\prime \prime} \mathrm{E}$. This 
may be correlated with prevailing meteorological conditions.

\section{Conclusions}

The recorded data reveals that Benzene, Toluene, ethyl benzene and Xylene were present at the selected locations. MATLAB developed scheme for Modified Quadratic Shapered Method was successfully run for the Constrained Visualization of BTEX spatial distribution.

\section{Acknowledgements}

The authors are thankful to Higher Education Commission (HEC) of Pakistan for sponsoring this study through Indigenous PhD Scholarship scheme.

\section{References}

[1] Y. Verma, et al., "Biological Monitoring of Exposure to Benzene in Traffic Policemen of North India," Industrial Health, Vol. 41, No. 3, 2003, pp. 260-264. doi: 10.2486/indhealth. 41.260

[2] J. Lynch, T. Bernath, et al., "Benzene in the Workplace," American Industrial Hygiene Association, Vol. 41, No. 9, 1980, pp. 616-623. doi:10.1080/15298668091425392

[3] US Environmental Protection Agency Office of Mobile Sources (USEPA), "Motor Vehicle Related Air Toxic Study EPA-420 (R-93-005)," US Environmental Protection Agency Office of Mobile Sources, Ann Arbor, 1993.

[4] S. E. Edgerton, et al., "Determination of Aromatic Hydrocarbons in Urban Air of Rome," Atmospheric Environment, Vol. 31, No. 4, 1989, pp. 557-566.

[5] T. R. Lewis and W. J. Moorman, "Long Term Exposure to Auto Exhaust and Other Pollutant Mixtures," Archives of Environmental Health, Vol. 29, No. 2, 1974, pp. 2-6.

[6] A. Srivastava, et al., "Ambient Levels of Benzene in Mumbai City," International Journal of Environmental Health Research, Vol. 14, No. 3, 2004, pp. 215-222. doi:10.1080/0960312042000218624

[7] A Hussam, et al., "Solid Phase Micro Extraction: Measurement of Volatile Organic Compounds (VOCs) in Dhaka City Air Pollution," Journal of Environmental Science and Health, Part A, Vol. 37, No. 7, 2002, pp.

\section{3-1239. doi:10.1081/ESE-120005982}

[8] P. K. Srivastava, et al., "Ambient Levels of Benzene and Other Aromatic Hydrocarbons in Mumbai," Proceedings of Nature on Environment, B'lore Univ, June 2000, pp.710.

[9] D. K. Biswas and G. D Pandey, "Strategy and Policy Adopted in Air Quality Management in India," Proceedings of Better Air Quality in Asian and Pacific Rim Cities (BAQ 2002), Hong Kong, 16-18 December 2002.

[10] G. Badar, et al., "Development of Baseline (Air Quality) Data in Pakistan," Environmental Monitoring and Assessment, Vol. 127, No. 1-3, 2007, pp. 237-252. doi:10.1007/s10661-006-9276-8

[11] L. Husain, et al., "Application of the $\mathrm{SO}_{4}^{2-} / \mathrm{Se}$ Tracer Technique to Study $\mathrm{SO}_{2}$ Oxidation in Cloud and Fog on a Time Scale of Minutes," Chemosphere, Vol. 54, No. 2, 2004, pp. 177-183. doi:10.1016/S0045-6535(03)00531-9

[12] S. Hameed, et al., "On the Widespread Winter Fog in Northeastern Pakistan and India," Geophysical Research Letters, Vol. 27, No. 13, 2000, pp. 1891-1894. doi:10.1029/1999GL011020

[13] N. F. Qadir, "Air Quality Management in Pakistani Cities: Trends and Challenges," Better Air Quality in Asian and Pacific Rim Cities (BAQ 2002), Hong Kong, 16-18 December 2002.

[14] United Nations Development Program Pakistan (UNDP)/ World Bank Energy Sector Management Assistant Program, "Pakistan Clean Fuels," Pakistan, October 2001.

[15] G. Mustafa, et al., "Gridding Multivariate Positive Data for Real Time Visualization," Proceedings of the International Conference on Computer Graphics, Imaging and Visualization, Sydney, 26-28 July 2006, pp. 496-502.

[16] D. Shepard, “A Two-Dimensional Interpolation Function for Irregularly Spaced Data," Proceedings of 23rd ACM National Conference, New York, 1968, pp. 517-523. doi: $10.1145 / 800186.810616$

[17] W. J. Gordon and J. A. Wixom, "Shepard's Method of 'Metric Interpolation' to Bivariate and Multivariate Interpolation," Mathematics of Computation, Vol. 32, No. 141, 1978, pp. 253-264. doi:10.2307/2006273

[18] R. Franke and G. Neilson, "Smooth Interpolation of Large Set of Scattered Data," International Journal of Numerical Methods in Engineering, Vol. 15, No. 11, 1980, pp. 1691-1704. doi:10.1002/nme.1620151110 